\title{
Cirkels in het hart
}

Citation for published version (APA):

Allessie, M. A. (1985). Cirkels in het hart. Maastricht University. https://doi.org/10.26481/spe.19851101ma

Document status and date:

Published: 01/11/1985

DOI:

10.26481/spe.19851101ma

Document Version:

Publisher's PDF, also known as Version of record

\section{Please check the document version of this publication:}

- A submitted manuscript is the version of the article upon submission and before peer-review. There can be important differences between the submitted version and the official published version of record.

People interested in the research are advised to contact the author for the final version of the publication, or visit the DOI to the publisher's website.

- The final author version and the galley proof are versions of the publication after peer review.

- The final published version features the final layout of the paper including the volume, issue and page numbers.

Link to publication

\footnotetext{
General rights rights.

- You may freely distribute the URL identifying the publication in the public portal. please follow below link for the End User Agreement:

www.umlib.nl/taverne-license

Take down policy

If you believe that this document breaches copyright please contact us at:

repository@maastrichtuniversity.nl

providing details and we will investigate your claim.
}

Copyright and moral rights for the publications made accessible in the public portal are retained by the authors and/or other copyright owners and it is a condition of accessing publications that users recognise and abide by the legal requirements associated with these

- Users may download and print one copy of any publication from the public portal for the purpose of private study or research.

- You may not further distribute the material or use it for any profit-making activity or commercial gain

If the publication is distributed under the terms of Article $25 \mathrm{fa}$ of the Dutch Copyright Act, indicated by the "Taverne" license above, 
C I R K E L I N HE T HART

\section{REDE}

Uitgesproken bij de aanvaarding van het ambt van hoogleraar in de FYSIOLOGIE

aan de Rijksuniversitelt Limburg op vrijdag 1 november 1985

door

DR. M. A. ALIESSIE 

Dames en Heren,

De keuze van het onderwerp voor mi in inauguralle rede was niet zo moeilijk. Verreweg het grootste deel van mijn wetenschappelijke activiteit is gericht geweest op de bestudering van een uitermate boeiend en nog steeds intrigerend verschijnsel, dat van cirkelgeleiding van de electrische impuls in het hart. Ik wil dan ook van de gelegenheid die mij vandaag wordt geboden gebrulk maken $U$ daar iets over te vertellen.

Cirkels in het hart heb je in vele maten en soorten. Fn zoals we zullen zien zijn deze verantwoordellj jk voor een breed scala van ritmestoornissen van het hart. Sommlge zi jn tameli.jk onschuldig, andere alleen maar lastig, terwijl er ook zeer kwaadaardige cirkels bestaan die binnen enkele minuten tot plotselinge hartdood kunnen leiden.

Als fysioloog heb ik me vooral bezig gehouden met de meer fundamentele aspecten van dit belangrijke klinische probleem en door dierexperimenteel onderzoek getracht een beter inzicht in het hoe en waarom van dit verschijnsel te krijgen. Het gaat hierbij on vragen als: waarom gedraagt de ene cirkel zich zo anders dan een ander, welke omstandigheden in het hart vergroten de kans op het ontstaan van cirkelgeleiding, en hoe kunnen we met geneesmiddelen of chirurgie de finctionele of structurele eigenschappen van het hart zodanig veranderen dat cirkels geen kans meer krijgen. Pas indien we een goed inzicht hebben in de eigenschappen en het gedrag van de verschillende vormen van cirkelgeleiding, kunnen we hopen langs rationele weg oplossingen te vinden om ritmestoornissen op adequate wijze te bestrijden.

Maar alvorens we ons met het optreden van cirkels kunnen bezig houden, moeten we eerst eens kijken hoe het hart nomaal functioneert. Zoals U allen uit eigen ervaring weet klopt ons hart normal min of meer regelmatig, waarbij de hartfrequentie door ons autonome zenuwstelsel binnen 
bepalde gretzen aan de onstandigheden kan worden angepast. De oorsprong van ons normale hartritme is gezeteld in een klein groepje cellen hoog in het hart dat gespecialiseerd is in het zelf regelmatig genereren van electrische Impulsen. Het is deze speciale groep cellen, ook wel sinusknoop genaamd, die optreedt als de natumlijke pacemaker van het hart. In het Fyslologisch Laboratorium aan de Universitelt van Ansterdam, waar ik mijn opleiding tot fysioloog heb gekregen, is onder leiding van mijn leemeester Bouman veel onderzoek gedaan naar de cellulaire achtergronden van deze nomale automatie van het hart. Door met behulp van microelectroden de electrische activiteit van ëén enkele cel af te leiden hebben zij kunnen vaststellen waar precies binnen de sinusknoop de electrische impuls ontstaat en hoe de ontladingsfrequentie van deze cellen wordt geregeld vila de autonome zenuwen.

Behalve automatie is een andere belangrijke eigenschap van het hart dat de electrilsche impuls -nadat deze ergens is ontstaan- snel over de rest van het hart van cel tot cel wordt voortgeleld. Op deze manier worden alle hartcellen in korte tijd synchroon tot ontlading gebracht. Deze synchroniciteit is van essentieel belang omdat alleen als alle hartspiercellen zich op hetzelfde moment samentrekken het hart als geheel een bepaalde hoeveelheid bloed kan uitpompen.

In werkelijkheid verloopt de normale activatie van het hart iets gecompliceerder en bestaat het zoogdierenhart zoals U weet wit vier compartimerten, de rechter en linker boezam en de rechter en linker kamer. De impuls die in de sinusknoop ontstat breidt zich eerst ult over belde boezems, maar loopt dan dood op een bindweefselring die de boezens en kamers electrisch van elkaar scheldt. Alleen in het centrum van het hart bestaat er een nauwe electrische verblinding, die gevormd wordt door weer een andere knoop van cellen, de atrlo-ventriculaire knoop of kortweg Av-knoop. In deze nawe verbinding wordt de electrische impuls even vertraagd alvorens naar de kamers over te 
steken, waardoor het bloed de tijd krijgt vanuit de boezens de hartkamers te vullen. Tenslotte worden ook de kamers snel vanuit de AV-knoop geactiveerd, waarbif de impuls eerst naar beneden, naar de punt van het hart loopt, om daarna weer naar boven te geleiden. Cok nu zorgt het bindweefselschot er weer voor dat, zodra het hele hart Eén keer tot ontlading is gebracht, de impuls netjes uitdooft en de hartcellen zich kunnen herstellen om vervolgens te wachten op een nleute impuls vanuit de sinusknoop. We zien dus dat, hoewel het hart zelf rond is, het ontstaan van een cirkel in het hart wordt tegengegaan door de aanwezlgheld van een isolerend tussenschot.

\section{DE ANATOMISCHE GIRKEL}

Continue cirkelgeleiding in hartweefsel werd voor het eerst beschreven door Mines in 1913. Deze onderzoeker gebrulkte voor zijn experimenten het geisoleerde hart van de schildpad. In deze lagere diersoort is (in tegenstelling tot het dikke en stevige schild dat het dier ongeeft) het bindweefselschot in het hart minder goed ontwikkeld en bestaat er op meerdere plaatsen electrisch contact tussen boezems en kamers. Indien het hart langs operatleve weg wordt verwijderd en snel in een weefselbakje wordt geplaatst kan het gedurende vele uren in leven worden gehouden door het met een geschikte vloeistof van de juiste samenstelling te doorstromen. In een dergelijk geisoleerd ringvormig preparaat is Mines er in 1913 in geslaagd experimenteel een langdurige tachycardie (= aanval van te snelle hartactie) op te wekken. Voorts kon hij aantonen dat het mechanisme van deze kunstmatige ritmestoornis was gebaseerd op een continue rondtollen van de electrische impuls in de ring. De volgorde van activatie verlfep hierbij van atriumsegment 1 naar atriumsegment 2, via een electrische verbinding van hieruit naar het eerste kamersegment, vervolgens naar het tweede kamersegment en 
tenslotte via een andere verbinding tussen boezems en kamers weer terug naar atriumsegment 1 ...... enzovoort.

Onder nomale onstandigheden zal een impuls zich langs beide zi jden van de ring voortplanten, ến met de klok mee en de andere tegen de klok in. Deze twee tegengesteld drailende golffronten zullen vervolgens ergens aan de overkant van de ring op elkaar botsen en daardoor beiden ultdoven. Ondex bijzondere omstandigheden kan het echter voorkomen dat de electrische impuls slechts in én richting van start gaat en in de andere richting blokkeert. Als bil jwoorbeeld de met de klok mee draaiende impuls blokkeert, zal de tegen de klok indraaiende impuls nú aan de overkant van de ring géen tegenligger op zijn weg vinden en is ex geen enkele reden warom de impuls niet doorgat en een hếl rondje aflegt. Als de condities gunstig zijn kan het zelfs gebeuren dat de impuls gevangen wordt in zijn eigen rondgang en elndeloos gaat rondcirkelen. Dit laatste zal gebeuren indien, op het moment dat de impuls na zijn eerste rondje op zijn ultgangspunt terugkeert, de hartcellen aldaar hun prikkelbaarheid weer hebben hersteld. De kans hierop is des te groter naarmate het anatomische circuit groter is of de geleiding van de impuls in de ring langzaam gaat (dan is de rondetijd van de impuls relatief lang en is er veel tijd beschikbaar voor het herstel van de prikkelbaarheid).

Samengevat zijn de omstandigheden waaronder cirkelgelelding in het hart kan ontstaan:

1. untdrectioneel blok van de inpuls.

2. trage gelelding of een grote omweg.

3. opnieuw binnendringen van het gebled war de impuls is ontstaan (reentry).

Tot zover de beschrijuing van een fysiologisch experiment uit de oude doos.

Maar, zo zult 0 zich afvragen, wat heeft een dergelijke warneming aan een schildpaddenhart nu te maken met 
ritmestoomissen bij de mens? Ik heb immers aan het begin van mijn betoog verteld dat het mensenhart door de aanwezigheid van een isolerend bindweefselschot tussen boezems en kamers beschermd was tegen dit soort cirkelgeleiding. In de jaren volgend op het klassieke experiment van Mines verschenen er een aantal pathologisch anatomische studies waarin een tamelijk zeldzame aangeboren afwijking aan het hart werd beschreven waarbij er naast de normale verbinding ë́n of meerdere extra electrische verbindingen tussen boezem en kamer werden beschreven. Tijdens de embryonale ontwikkeling zijn sommige van ons kennelijk het schildpaddenstadium niet te boven gekomen en $z i j n$ er meerdere electrische verbindingen bli jven bestaan.

Het is eén van de grote verdiensten geweest van Durrer en Wellens in de jaren zestig en begin zeventig in de cardiologische kliniek te Amsterdam door systematisch klinisch electrofysiologisch onderzoek van patienten met deze aangeboren afwijking het bewijs te leveren dat de aanvallen van tachycardie (hartkloppingen) die bij deze mensen op kunnen treden, veroorzaakt worden door cirkelgeleiding van de electrische impuls in een groot anatomische circuit gevormd door atriumweef sel, $A V$-knoop, bundel van His, kamernyocard en de abnornale extra verbinding.

In de meeste gevallen kunner de ritmestoornissen onderdrukt worden met bepalde geneesmiddelen die de electrofysiologische eigenschappen van het circuit beinvloeden. In andere gevallen is een operatie aangewezen waarbif de abnormale verbinding wordt opgezocht en doorgesneden om aldus het weeffoutje van de natuur te corrigeren. Dit is echter beslist géen routine operatie, maar kan tegenwoordig toch in speciale centra waar cardioloog, hartchirurg en electrofysioloog samenwerken, met een laag risico worden ultgevoerd.

Dit korte historische overzicht leert ons een aantal dingen. In de eerste plaats vind ik het een mool voorbeeld hoe bepaald fundamenteel onderzoek, zoals experimenten aan 
een schildpaddenhart, warvan in eerste instantie de maatschappelijke relevantie ver te zoeken is, op den duur van cruciaal belang blijkt te zijn voor de directe gezondheldszorg. In de tweede plaats zien we dat bij de oplossing van het probleem een aantal zeer uitlopende disciplines betrokken zijn geweest (fysiologie, pathologische anatomie, cardiologie, farmacologie, chirurgle). En tenslotte valt op dat het zo'n 70 jaar heeft gedurd voordat het concept van de anatomische clrkel is uitgemond in een rationele therapie. Gedegen wetenschap heeft veel tijd nodig en laat zich nilet dwingen. In deze tijd van forse bezuinigingen op wetenschappelijk onderzoek en onderwijs, vind ik het belangrijk hler nog eens nadrukkelijk op te wijzen. We moeten oppassen met de reorganisatie van het wetenschappelijk onderzoek in Nederland niet door te slaan naar de andere kant en met name risicodragend onderzoek onmogelijk te maken. Een belangrijk en onvermijdelijk aspect van grensverleggend onderzoek is dat het eerst vaak mislukt, vaak moet mislukken voordat een stapje voorult kan worden gemaakt. Ik weet dat dit moeilijk aan beleidsmakers is uit te leggen, maar het is nu eenmaal een feit dat de weg in de wetenschap vaak een bijzonder grillige is die uitermate moeilijk van te voren precies is te plannen. Maar laten we niet te ver afdwalen en ons verliezen in allerlei filosofische en politieke bespiegelingen en terugkeren naar ons eigenlijke onderwerp.

FYSIOLOGISCHE CIRKELS

Uit mijn verhaal tot nu toe zou wellicht de indruk kumen ontstaan dat de identificatie van anatomische cirke1s in het hart het probleem van de ritmestoornissen heeft opgelost. Niets is echter minder waar! Het hier beschreven mechanisme van de anatomische cirkel, gebaseerd op een aangeboren hartafwijking, verklaart slechts een zéér 
klein gedeelte van het totaal aan ritmestoomissen bij de mens. Verreweg de meeste ritmestoomissen treden op zonder dat wan een aangeboren cirkel sprake is. Anno 1985 is het onderzoek naar de achtergronden van ritmestoomissen van het hart dan ook nog in volle gang. Het begint zo langzamerhand duidelijk te worden dat er naast anatomische cirkels ook nog andere typen cirkels in het hart kunnen bestaan. In de rest van mijn betoog wil ik op twee andere vomen van cirkelgeleiding -te weten fysiologische en pathologische cirkels- wat dieper ingaan.

In de tijd dat ik nog maar net in het fyslologlsch laboratorium te Amsterdam werkzaam was, werd daar door Bonke en Bouman een toevallige waameming gedaan. Om geheel. andere redenen die nu te ver voeren, bestudeerden $21 j$ de reactie van een klein stukje geisoleerd konijnenatrium op zogenaande vroege prikkels. Daarbij vonden zij dat bij wijze van hoge uitzondering het toedienen van een vroege electrische prikkel niet door slechts én activatle werd gevolgd (zoals normaal het geval ls), maar door een hele reeks snelle ontladingen. Hierbil was behalve de plaats van prikkelen ook met name het moment warop de vroege prikkel werd gegeven van groot belang. De snelle reeks ontladingen trad alléén op bij een kritisch koppelingsinterval ten opzichte van de voorafgaande normale slag.

Wat was hier aan de hand? Gezien de kleine afmetingen van het preparaat en het ontbreken van een anatomisch obstakel kon hier van een anatomische cirkel geen sprake zijn. Hadden we hier te maken met een abnomale vorm van automatie, het op gang brengen van een te snelle pacemaker in het hart? of was hier toch sprake van een of andere vorm van clrkelgeleiding? We besloten deze vaag tot kernvraag van ons onderzoek te maken en zijn er in een reeks van jaren in geslaagd stukje bij beetje het mechanisme van dit verschi jnsel te ontrafelen.

De beste methode on er achter te komen met welk mechanisme we hier te maken hadden 1 is het rechtstreeks zichtbaar maken van de electrische activatie van het hart - 
of in dit geval- van een klein stukje hartspier. In geval van abnormale automatie verwacht je dat de electrische impuls zich vanuit érn plaats (de plaats van de abnormale pacemaker) over het hart zal uitbreiden, terwijl bij cirkelgeleiding er ergens een circuit zichtbaar zal moeten worden. Het probleem hierbij was echter dat je in de afwezigheld van een duidelijk anatomisch geleidingspad, voor het nauwkeurig in kaart brengen van de electrische activatie, op honderden verschillende plaatsen de electrische activitelt moest meten. In de beginjaren zeventig warin dit onderzoek zich af speelde was de stand van de electronica nog zodanig dat hier een onhandelbaar grote hoeveelheid apparatuur voor nodig zou zijn. We hebben daarom noodgedwongen gekozen voor een compromis en met een 10-voudige electrode het hart afgetast. In een later stadium zijn we er toe overgegaan om met microelectroden dit verschijnsel nog naukeuriger te bestuderen.

op deze manier kon de wijze waarop de electrische impuls zich tijdens deze zeer snelle aritmie over het preparaat voortplantte volledig en nauwkeurig worden gereconstrueerd. Uit deze electrische activatiekaarten kon rechtstreeks worden afgelezen dat we hier niet te maken hadden met eến of andere vorm van abnormale impulsworming, maar met een nieuw type cirkelgeleiding. Het nieuwe bestond hierin dat de impuls niet in een anatomisch gedefinieerd circuit rondcirkelde, maar in een gedeelte van de hartspier waarin zich geen anatomisch obstakel bevond. De rondetijden van deze cirkelbewegingen waren precies gelijk aan het tifdsinterval tussen de opeenvolgende impulsen van de aritmie. De diameter van de micro-cirkel bedroeg slechts enkele millimeters en kon alleen zichtbaar worden gemaakt dankzly de grote hoeveelheid signalen die onder laboratorium condities kon worden afgeleid.

De vraag die zich onniddellijk opdringt bij het zien van een dergelijk mechanisme is wat er zIch, bij het ontbreken van een centraal anatomisch obstakel, in het centrum van zo'n fysiologisch circuit afspeelt. Uit 
metingen met microelectroden is gebleken dat het centrum van dergelijke cirkels centripetaal vanuit het rondcirkelende activatiefront wordt geactiveerd. Dat wil zeggen dat het "oog" van het circult In dit geval wordt gevormd door een aantal convergerende, tegen elkaar botsende en elkaar voortdurend uitdovende kleine golffronten.

Een belangrijk kenmerk van een fysiologische cirkel is dat de impuls in een zo klein mogelijk circult rondcirkelt. Nergens in het circuit bevindt zich hartweefsel war de prikkelbaarheid volledig is herstelt. Immers, indien dit het geval is, zou de impuls een gedeelte van het circuit kumnen afsnijden waardoor automatisch de dimensie van de cirkel kleiner wordt. Een andere belangrijke elgenschap is dat de omlooptijd van de impuls zo kort mogeli jk is en daarmee de frequentie van de aritmie zeer hoog.

Evenals na de beschrijving van de anatomische cirkel in het schildpadden hart, deed zich ook hier weer de vraag voor of de ontdekking van deze kleine electrische draaikolkjes in het koni jnenhart van betekenis was voor de verklaring van ritmestoornissen bij de mens. of dat we hier te maken hadden met een weliswaar interessant mar overigens kunstmatig fenomeen dat zich alleen onder bijzondere omstandigheden binnen het laboratorium voortdeed.

Op het moment dat we met deze vraag geconfronteerd werden deed zich de gelukklge onstandigheld voor dat de Nederlandse regering besloot een Medische Faculteit, ja zelfs een volwaardige Universitelt in Zuid Limburg te stichten. Behalve de vele positieve effecten die deze beslissing voor de reglo zuld Limburg heeft gehad en nog heeft, was dit ook van essentiele betekenis voor de voortgang van ons onderzoek. Onder de bezlelende lelding van Reneman werd gekozen voor een fyslolog 1 sch laboratorium dat zich primair zou richten op research naar de oorzaken en gevolgen van hart en vaatziekten. Als onderdeel hiervan kon in Maastricht een electrofysiologisch laboratorium 
worden opgezet waar de techniek on de electrische activatie van het hart in kaart te brengen centraal staat. Dankzij de stormachtige ontwikkelingen in de electronica en computertechnologie hebben we thans de beschilking over een mapping systeen waarmee in éen klap op 192 verschillende plattsen de lokale electrische activiteit kan worden afgeleid en ongezet in kleur gecodeerde activatiekarten. Met een dergell.jk uitgebreld systeem kon de speurtocht naar cirkels in het hart nu ook in grotere zoogdierharten worden voortgezet. We hebben ons hierbij in eerste instantie gericht op ritmestoornissen in de hartboezens zoals boezemfladderen en fibrllleren en hebben aangetoond dat deze arftmieen ook in het hondenhart gebaseerd zifn op fysiologische cirkels. Bij boezenfladderen, een zeer snel maar toch nog regelmatig ritme, bleek er één cirke1 te bestaan. Het fyslologische karakter van deze cirkel wordt benadrukt door het feit dat de localisatie van deze cirkels iedere keer anders was en zelfs in hetzelfde hart tijdens verschillende aanvallen van boezemfladderen kon verschillen. Tijdens, fibrilleren, een niet alleen zeer snel maar ook sterk onregelmatig ritme waarbij de pompfunctie van het hart plotseling geheel verloren gaat, kon worden aangetoond dat er meerdere fysiologische cirkels tegelijkertijd door de hartspier zwierven.

Het moge verwondering wekken dat de belangrijkste ritmestoornis van het hart, het fibrilleren dat, indien dit in de kamers optreedt, tot plotselinge hartdood leidt, in wezen gebaseerd is op een fysiologisch mechanisme. Ieder normal gezond mensenhart zal fibrilleren indien de aanwezlge coördinatie tussen de hartcellen voldoende sterk wordt verstoord. Deze wetenschap zorgt ervoor dat we onze kinderen verbieden met hun vingers in het stopcontact te peuteren, want 220 Volt wisselspanning is een van de zekere manieren on dit voor elkaar te krijgen. Een andere veel belangrijker oorzaak voor het ontstaan van fibrilleren is het acute hartinfarct. De electrische processen die zich hierbij afspelen zijn uitgebreid door de groep van Janse in 
Amsterdam onderzocht. Daarbij is waarschijnlijk genaakt dat lokale stromen tussen het zieke en gezonde deel van de hartspier de rol van het stopcontact kurnen overnemen waardoor het normale hartritme plotseling overgaat in fibrilleren. Het is dus niet het proces van fibrilleren zelf dat abnormaal is, nee het abnomale zit hem in het op gang brengen, het ontstaan van deze dodelijke ritmestoornis. Dit verklaart ook het grote succes van de zgn. hartbewaking bij een hartaanval. Indien onverhoopt fibrilleren optreedt, maar er worden snel maatregelen genomen om het hart weer in de pas te brengen, kan het hart weer normaal verder kloppen, waardoor het hartinfarct de kans krijgt om langs natuurlijke weg te genezen.

\section{PATHOLOGISCHE: CIRKELS}

Indien we nu het scala van ritmestoornissen overzien die veroorzaakt worden door cirkelgeleiding in het hart, is er nog éên belangrijke aritmie onbesproken gebleven, te weten de kamertachycardie die na het doormaken van een hartinfarct kan optreden. Tijdens het genezingsproces van een hartinfarct treden er allerlei structurele en functionele veranderingen op in het gedeelte van de hartspler dat door het infarct werd getroffen. De eigenschappen en het gedrag van cirkelgeleiding in dergelijk pathologisch hartweefsel zijn ook duidelijk anders dan de elgenschappen van anatomische dan wel fysiologische cirkels. Hoewel het onderzoek van deze pathologische cirkels moelifjk is en nog in de kinderschoenen staat $11 j k t$ de pathologische cirkel in zijn eigenschappen een mengrorm van de puur anatomische en fysiologische cirkel te zijn. Hieronder zijn de belangrijkste kenmerken van de drie types van cirkelgeleiding naast elkaar gezet. 
1. Groot

2. Traag

3. Prikkelbaar segment

4. Stabial

5. Chirurgie kan
Kein

Snel

Niet

Onstable1
Klein

Matig Snel

Prikkelbaar segment Stabie1

Chirurgie kan

6. Reageren alledrie terschillend op geneesmiddelen

Samen met Prof. Wit uit New York die de afgelopen maanden ons laboratorium tijdelijk is komen versterken hebben we onderzoek gedaan naar dit soort cirkels in abnomaal hartweefsel 4-7 dagen na het doormaken van een hartinfarct. Experimenteel kunnen we door het afsluiten van een tak van de kransslagaderen een hartinfarct maken waardoor een gedeelte van de hartspier afsterft. Vaak is het hierbij zo dat zowel aan de binnen- als aan de buitenkant van het hart een dun laagje hartcellen overleeft. Met behulp van een multipele afleidelectrode hebben we de geleldingseigenschappen in deze dunne laag onderzocht. Eên wan de dingen die daarbij werd gevonden is dat de impulsgeleiding in dit abnormale hartweefsel een dufidelijke voorkeursrichting vertoont die samenhangt met de vezelrichting van de hartcellen. Hierbij kan de geleidingssnelheid dwars op de spiervezels meer dan vijf keer vertraagd zijn doordat, naar we aannemen, de celcontacten tussen deze zleke cellen verstoord is. Cirkelgeleiding in een dergelijk zlek gedeelte van de hartspler ziet er dan ook anders uit. In de eerste plaats wordt als gevolg van de grote verschillen in geleidingssnelheid, de cirkel vervormd tot een ellips, waarbij de lange as van de ellips parallel loopt aan de vezelrichting. In de tweede plaats, en dat is klinisch erg belangrijk, is de omlooptijd van de impuls in een dergelljke ellips langer dan in de pur fyslologische cirkel en ontstaat er dientengevolge een prikkelbaar 
segment in het circuit waardoor de cirkelbeweging een hoge mate van stabiliteit krijgt en de kans dat de ritmestoorins uit zich zelf zal stoppen gering is. Het moge duidelijk zijn dat het voor de behandeling van dergelijke ritmestoornissen essentieel is dat we ook de karakteristieken van dit type cirkelgeleiding goed leren kennen. Zo ver zijn we helaas op dit moment nog niet. Wel hebben we zeer recent als eerste stap bovenstaande ideëen getest in een binnen onze groep door Lammers ontwikkeld computermodel. Hierbij bleek dat door het invoeren van verschillen in geleidingssnelheid in verschillende richtingen inderdaad de hier boven beschreven verschijnselen optreden. De cirkel verandert in een ellips en door de trage geleiding bij de keerpunten van de ellips wordt het totale circuit langzamer en ontstaat er en prikkelbaar segment. Mar zoals ik al zel stat dit onderzoek naar zieke cirkels pas in zijn kinderschoenen en zal er nog veel onderzoek moeten gebeuren om de verschillende variëteiten van pathologische cirkels te leren kennen.

Tenslotte als afronding een blik in de toekomst. Ons onderzoek is in een fase gekonen waarbij meer en meer de nadruk zal komen te liggen op de pathofysiologie. Dit kan enerzijds door bepaalde ziekteprocessen in computer- en diemodellen na te bootsen, maar aan de andere kant is het niet altijd mogelijk de pathologische veranderingen zoals die zich bij de mens voltrekken volledig te imiteren. Daarom is het strikt noodzakelijk de resultaten en ldeeen die voortkomen uit fundamenteel onderzoek in de kliniek te toetsen. De vooruitzichten voor een intensleve samenwerking tussen de capaciteltsgroepen Fysiologie en Cardiologile zijn uitstekend en zullen nog een extra injectie krijgen door de stimulerings subsidie van 3.25 miljoen die door het ministerie van 0 en voor een verdere versterking van de Infra structurr aan beide groepen is toegekend. In dit verband is ook de komst van de hartchirurgle naar 
Maastricht van grote betekenis. Het is dan ook mijn diepe wens dat we er de komende jaren in zullen slagen onze research organisatie op het gebled van hart en vatziekten verder uit te bouwen en de kwalltelt ervan nog meer te verhogen. Snelle gemakkelijke successen moet U hierbij niet verwachten. We leven in een tijd dat de kans op min of meer toevallige doorbraken steeds onwaarschijnlijker wordt. Voortgang in de geneeskunde kan slechts bereikt worden dankzij de voortdurende Inspanning van een groep goede en creatieve onderzoekers in een optimale ongeving. Daarbif is het nodig tot het cellulaire en soms zelfs moleculaire niveau af te dalen ondat de eigenlijke oorzaken van hart en vaatzlekten zich daar af spelen. Ik ben ex van overtuigd dat Maastricht Ën van de plaatsen is war dit gerealiseerd kan worden.

\section{Dames en Heren,}

Aan het einde van mijn voordracht gekomen wil $1 \mathrm{k}$ U allen danken dat $U$ in $z$ grote getale vandaag hier hebt willen komen. Ik heb geprobeerd $\mathrm{U}$ een $\mathrm{kijkje} \mathrm{te} \mathrm{geven} \mathrm{in} \mathrm{de} \mathrm{keuken}$ van het wetenschappelijk bedrijf en hoop dat $1 k$ er in geslaagd ben iets van de grote ultdaging en de betekenis van wetenschappelijk onderzoek op U over te dragen.

Ook wil ik niet afsluiten zonder allen met wie ik in de afgelopen jaren heb samengewerkt mijn dankbaarheid te betulgen. In het bijzonder denk ik daarbij aan Prof Bouman die als leider van de hartgroep in het Fysiologisch laboratorium te Ansterdam $\mathrm{mij}$ voortdurend gestimileerd en geinsplteerd heeft. Met name de grote individuele vrijheld die tik vanaf het begin af an als jong onderzoeker heb gekregen is lets war ik in toenemende mate, nu we in een tijd leven war dit steeds moeilijker wordt, de grote betekenis van inzie. Ik heb het geluk gehad in mijn Ansterdamse periode als hecht trio samen met Vic Bonke en Francien Wilms-Schopman onderzoek te mogen doen. We zijn niet alleen met aljn driẻen een succesvol team gebleken, maar we hebben ook tegelijkertijd ontzettend veel plezier 
gehad. Of zoals een nestor uit ons vak weleens gezegd heeft: "Als de ambtenaren in Den Haag wisten hoe leuk ons werk was zouden ze het zeker verbieden" :

Dok bewaar ik goede herinneringen aan de samenwerking met Giel Janse en Frans van Capelle van de afdeling experimentele cardiologie. Laatst kwam ik bij het opruimen van een oude kast nog een onderzoeks protocol tegen waar boven stond "MAUVIFRAFRAGIE". Dit samenraapsel van afkortingen van voornamen was onze manier on de deelnemers aan een experiment te noteren. Wat een genot dat we destijds rustig met zijn vijfen een hele dag een proef konden doen!

Ook. mijn overgang naar de capaciteltsgroep Fysiologle nu al weer bijna tien jaar geleden is een heel gelukkige gebleken. Ik wil hier dan ook graag alle medewerkers van onze capaciteitsgroep bedanken voor hun collegialiteit in tijden van voorspoed en hun solidariteit bij tegenspoed. In het bijzonder denk ik daarbij natuurlijk aan de subgroep electrofysiologie met als vaste kern Wim Lammers, Vic Bonke en Jan Hollen. Hoe jullie miljn voortdurende gedram, sons chaotische 1ijkende aanpak en chronisch ongeduld al die tijd hebben verdragen is althans mij een raadsel.

Een allesbepalende factor in de opbouw en de consolidatie van zowel onze onderzoeks organisatie als onze capaciteltsgroep is geweest Rob Reneman. Het kan mijns inziens niet genoeg benadrukt worden hoe belangrijk de rol van een natuurlijke leider is voor de werksfeer en het welslagen van een groep. Tk heb daar persoonlljk zeer sterk van geprofiteerd en Rob ik leer nog dagelijks van je, of het nu is op het gebied van management, viste, realiteitszin, of het hanteren van intermenselijke problemen.

Het zal uit mijn verhaal al wel duidelijk zifn geworden dat ik een jarenlange periode van intensieve en vruchthare samenwerking heb gehad met Vic Bonke. Het feit dat je je onlangs geroepen voelde tot het ambt van rector magnificus heeft daar helaas een nogal abrupt einde aan gemaakt. Ik 
ben je zeer dankbaar voor alles wat je voor me hebt gedaan en $\mathrm{kk}$ hoop dat de onderbreking in onze dagelijkse samenwerking slechts een tijjelijke zal blijken te zijn.

tenslotte de kleinste en belangrijkste cirkel in mijn bestaan:

Paula, Martijn, Michiel, Chamila Dank jullie wel.

Ik heb gezegd. 